\title{
Floating microspheres: a review
}

\author{
Jagtap Yogesh Mukund*, Bhujbal Rohan Kantilal, Ranpise Nisharani Sudhakar
}

\author{
STES's Sinhgad College of Pharmacy, Vadgaon (Bk.), Pune, India
}

\begin{abstract}
Gastric emptying is a complex process, one that is highly variable and that makes in vivo performance of drug delivery systems uncertain. A controlled drug delivery system with prolonged residence time in the stomach can be of great practical importance for drugs with an absorption window in the upper small intestine. The main limitations are attributed to the inter- and intra-subject variability of gastrointestinal (GI) transit time and to the non-uniformity of drug absorption throughout the alimentary canal. Floating or hydrodynamically controlled drug delivery systems are useful in such applications. Various gastroretentive dosage forms are available, including tablets, capsules, pills, laminated films, floating microspheres, granules and powders. Floating microspheres have been gaining attention due to the uniform distribution of these multiple-unit dosage forms in the stomach, which results in more reproducible drug absorption and reduced risk of local irritation. Such systems have more advantages over the single-unit dosage forms. The present review briefly addresses the physiology of the gastric emptying process with respect to floating drug delivery systems. The purpose of this review is to bring together the recent literature with respect to the method of preparation, and various parameters affecting the performance and characterization of floating microspheres.
\end{abstract}

Uniterms: Floating microspheres. Emulsion solvent diffusion-evaporation method. Drug delivery system. Release modifiers.

O esvaziamento gástrico é um processo complexo, com elevada variabilidade e responsável pela incerteza do desempenho dos medicamentos in vivo. Dessa forma, os sistemas de liberação modificada de fármacos, com tempo de residência prolongado no estômago, em especial, considerando aqueles fármacos com janela de absorção na porção superior do intestino delgado, apresentam fundamental importância. As principais limitações relativas à absorção do fármaco são, no geral, atribuídas à variabilidade inter e intra-paciente do tempo de trânsito gastro-intestinal (GI) e da não-uniformidade da absorção do fármaco na extensão do canal alimentar. Assim, justifica-se a utilização dos sistemas flutuantes ou hidrodinâmicos de liberação de fármacos. Vários medicamentos gastrorretentivos estão disponibilizados no mercado e incluem comprimidos, cápsulas, pílulas, filmes laminados, microesferas flutuantes, grânulos e pós. As microesferas flutuantes apresentam maior destaque em função da distribuição granulométrica uniforme dessas formulações de dose múltipla. Como resultado, a absorção do fármaco apresenta maior reprodutibilidade e os riscos associados à irritação local são reduzidos. Tais sistemas apresentam maior vantagem quando comparado às formulações de dose única. A presente revisão tem como objetivo apresentar as publicações recentes referentes aos métodos de preparação, os vários parâmetros que afetam o desempenho e a caracterização das microesferas flutuantes. Além disso, o presente trabalho aborda a fisiologia do processo de esvaziamento gástrico no que se refere aos sistemas flutuantes de liberação de fármacos.

Unitermos: Microesferas flutuantes. Método solvente da difusão-evaporação. Fármacos/liberação controlada. Modificadores de liberação.

\footnotetext{
*Correspondence: Jagtap Yogesh Mukund. STES's Sinhgad College of Pharmacy. S. No. 44/1, Vadgaon (Bk.), Pune-411 041, India. E-mail: yogeshjagtap2007@rediffmail.com
} 


\section{INTRODUCTION}

Among the different routes of drug administration, the oral route has achieved the most attention, partly due to the ease of administration and to the important flexibility in dosage form design (Soppimath et al., 2001). Unfortunately, in most cases, the important variability of the gastrointestinal tract physiology and of its transit time leads to unpredictable bioavailability and non reproducible therapeutic effects. One requisite for the successful performance of oral controlled release drug delivery systems is that the drug should have good absorption throughout the gastrointestinal tract (GIT), preferably by passive diffusion (Patil et al., 2006).

Most drugs are well absorbed throughout the entire intestinal tract, but some compounds, usually those that are polar in nature, are poorly absorbed from the large intestine. For such drugs, the main area from which absorption occurs is the small intestine. Some drugs may exploit a natural pathway, such as receptor-mediated transport, active transport or other specific transport mechanisms, and are known to have so-called "absorption windows" in the small intestine. Gastric emptying of dosage forms is an extremely variable process and the ability to prolong and control emptying time is a valuable asset for dosage forms that reside in the stomach for a longer period of time than conventional dosage forms (Shweta et al., 2005).

Several difficulties are faced in designing controlled release systems for better absorption and enhanced bioavailability. One of such difficulties is the inability to confine the dosage form in the desired area of the gastrointestinal tract. Drug absorption from the gastrointestinal tract is a complex procedure and is subject to many variables. It is widely acknowledged that the extent of gastrointestinal tract drug absorption is associated with time of contact with the small intestinal mucosa (Hirtz, 1985).

Gastroretentive systems can remain in the gastric region for several hours and hence significantly prolong the gastric residence time of drugs. Prolongation of gastric residence time (GRT) of a rate-controlled oral drug delivery system reduces inter-subject variability and the so-called "peak and valley" effect, leading to increased predictability and bioavailability of the dosage form, especially for molecules with a narrow absorption window. Moreover, the total gastrointestinal transit time is prolonged, thus, the number of dosage regimen can be reduced and solubility can be improved for drugs that are less soluble in a high $\mathrm{pH}$ environment.

The development of gastroretentive dosage forms capable of staying in the stomach over an extended period of time may be particularly useful for drugs that may act locally in the stomach, e.g., antacids, antibiotics for ulcers of bacterial origin (Franz, Oth, 1993); drugs that are absorbed primarily in the stomach, e.g., albuterol, chlordizepoxide (Sheth, Tossounian, 1978); drugs that absorbed rapidly from the GI tract, e.g., amoxicillin (Hilton, Deasy, 1992); drugs that have a narrow absorption window and are (mainly) absorbed from the upper small intestine, e.g., ofloxacin, levodopa, riboflavin, theophylline (Avachat, Dhamne, 2002; Sheth, Tossounian, 1979; Desai, Boltan, 1989); drugs having low bioavailability and drugs that degrade in the colon, e.g., ranitidine, metoprolol (Dave, Amin, Patel, 2004); and drugs that are poorly soluble in intestinal $\mathrm{pH}$, e.g., diazepam, weak bases such as dipyridamole (Hoffmann, 1979).

The controlled gastric retention of solid dosage forms may be achieved by the mechanisms of mucoadhesion (Ponchel, Irache, 1998; Gupta, Sau-Hung, Robinson, 1990), floatation (Deshpande et al., 1997), sedimentation (Rednick, Tucker, 1970; Davis et al., 1986), expansion (Urguhart, Theeuws, 1994; Mamajek, Moyer, 1980), modified shape systems (Fix, Cargill, Engle, 1993; Kedzierewicz et al., 1999), or by the simultaneous administration of pharmacological agents (Groning, Heun, 1984; Groning, Heun, 1989); that delay gastric emptying.

Some excipients, such as glycerol monooleate matrix (Paradkar et al., 2004) and Gelucire ${ }^{\circledR}$ (Chauhan et al., 2004), were also found to be gastro-retentive carrier systems, suitable for both polar and non-polar drugs.

Most of the floating systems reported in literature are single-unit systems, which are generally unreliable and non-reproducible in prolonging the GRT, in virtue of their unpredictable all-or-nothing emptying process. On the other hand, multiple-unit dosage forms appear to be better suited, since they claim to reduce inter-subject variability in absorption and have a lower dose-dumping probability (Singh, Kwon, 2000). The uniform distribution of these multiple unit dosage forms along the GIT could result in more reproducible drug absorption and reduced risk of local irritation; this gave way to the development of gastroretentive floating microspheres.

Floating microspheres are gastroretentive drug delivery systems based on a non-effervescent approach. Hollow microspheres, microballoons or floating microparticles are terms used synonymously for floating microspheres. Floating microspheres are, in a strict sense, spherical empty particles without a core. These are freeflowing particles, with size ranging from 1 to $1000 \mu \mathrm{m}$. Kawashima et al. (1992) have developed non-effervescent hollow polycarbonate microspheres by using an emulsion solvent evaporation method. This gastrointestinal transitcontrolled preparation is designed to float on gastric juice 
with a specific density of less than one. This property results in delayed transit through the stomach. The drug is released slowly at desired rate, resulting in increased gastric retention with reduced fluctuations in plasma drug concentration. The objective of the present review is to focus on the method of preparation, and the various parameters affecting the performance and characterization of floating microspheres. The present review is a source of detailed information about the various aspects of floating microspheres.

\section{Basic gastrointestinal tract physiology}

Anatomically, the stomach is divided into three regions: fundus, body, and antrum (pylorus). The proximal part made of fundus and body acts as a reservoir for undigested material, whereas the antrum is the main site for mixing motions and acts as a pump for gastric emptying, through propelling actions. Gastric emptying occurs during fasting as well as in fed states. The pattern of motility is, however, distinct in the two states. During the fasting state, an interdigestive series of electrical events takes place, cycling through both stomach and intestine every two to three hours. This is called the interdigestive myloelectric cycle or migrating myloelectric cycle (MMC), which is further divided into the following four phases, as described by Wilson and Washington (1989).

1. Phase I (basal phase) lasts from 40 to 60 minutes with rare contractions.

2. Phase II (preburst phase) lasts for 40 to 60 minutes with intermittent action potential and contractions. As the phase progresses, the intensity and frequency also increases gradually.

3. Phase III (burst phase) lasts for four to six minutes. It includes intense and regular contractions for a short period. It is due to this wave that all the undigested material is swept out of the stomach down to the small intestine. It is also known as the housekeeper wave.

4. Phase IV lasts for zero to five minutes and occurs between phases III and I of two consecutive cycles. After the ingestion of a mixed meal, the pattern of contractions changes from fasted to that of fed state. This is also known as digestive motility pattern and comprises continuous contractions as in phase II of the fasted state. These contractions result in reduced size of food particles (to less than $1 \mathrm{~mm}$ ), which are then propelled toward the pylorus in a suspension form. During the fed state, onset of MMC is delayed, resulting in slowdown of gastric emptying rate. Scintigraphic studies determining gastric emptying rates have revealed that orally administered controlled-release dosage forms are subject to basically two complications, namely short gastric residence time and unpredictable gastric emptying rate (Griffith et al., 1996; Wilding, Coupe, Davis, 2001). Various other methods have also demonstrated the variation in gastric emptying in humans under normal gravity conditions. Such methods include gastric aspiration (Maughan, Leiper, 1996), ultrasound (Holt et al., 1985; Dietrich, Braden, 2009), epigastric impedance (McClelland, Sutton, 1985), magnetic resonance imaging (MRI) techniques (Maughan, Leiper, 1996; Christmann et al., 1997), $\left[{ }^{13} \mathrm{C}\right]$-octanoic acid breath test (Ghoos et al., 1993) and Pellet Gastric Emptying Test (PGET) (Choe et al., 2001).

\section{Factors affecting gastric retention}

Gastric residence time of an oral dosage form is affected by several factors. In order to pass through the pyloric valve into the small intestine, particle size should be within the range of 1 to $2 \mathrm{~mm}$ (Wilson, Washington, 1989). The $\mathrm{pH}$ of the stomach in fasting state is $\sim 1.5$ to 2.0 and, in fed state, it is 2.0 to 6.0. A large volume of water administered with an oral dosage form raises the $\mathrm{pH}$ of stomach contents above 4 . The stomach does not have time to produce sufficient acid when the liquid empties the stomach; hence, basic drugs generally have a better chance of dissolving in fed state than in fasting state. The rate of gastric emptying depends mainly on viscosity, volume and on the caloric content of meals. Nutritive density of meals helps determine gastric emptying time. It does not make any difference whether the meal has high protein, fat or carbohydrate content, as long as the caloric content is the same (Hunt, Stubbs, 1975; Calbet, Maclean, 1997). However, increase in acidity and caloric value slows down gastric emptying. Velehik, Reynolds and Alavi (1989) have studied the effect of meal energy over gastric content. They have found that the time required to empty the stomach to half of its initial content $\left(\mathrm{T}_{1 / 2}\right)$ was 57,70 and 95 minutes for $150 \mathrm{kcal}, 300 \mathrm{kcal}$ and $600 \mathrm{kcal}$, respectively. Biological factors such as age, body mass index (BMI), gender, posture, and diseased states (Diabetes, Chron's disease) influence gastric emptying. In the case of elderly persons, gastric emptying is also slowed down. Generally, females have slower gastric emptying rates than males. Stress increases the rate of gastric emptying, while depression slows it down.

Alcohol and opioids reduce the rate of gastric empting, as do pain, fear, and anxiety (acting via the sympathetic nervous system which inhibits motility). Antimuscarinics, e.g., atropine, glycopyrrolate, also increase gastric emptying time. Metoclopramide, a prokinetic drug, 
is a centrally and peripherally acting dopaminergic D2 antagonist that increases the rate of gastric emptying and small intestinal transit, and also increases lower oesophageal sphincter constriction. Domperidone has a similar pharmacological action as that of metoclopramide. The macrolide antibiotic erythromycin has prokinetic properties. It is an agonist at motilin receptors, stimulating strong antral contractions. Anti-cholinesterases, e.g., neostigmine decreases the gastric emptying time (Jolliffe, 2009).

The resting volume of the stomach is 25 to $50 \mathrm{~mL}$. Volume of liquids administered affects gastric emptying time. When volume is large, emptying is faster. Fluids taken at body temperature leave the stomach faster than colder or warmer fluids. Studies have revealed that gastric emptying of a dosage form in the fed state can also be influenced by its size. Small-sized tablets leave the stomach during the digestive phase, while the large-sized tablets are emptied during the housekeeping waves (Oth, Franz, Timmermans, 1992). The above data is again supported by the study carried out by Rhie et al. (1998). They have found smaller pellets $(0.7 \mathrm{~mm})$ emptying during fed state and larger pellets $(3.6 \mathrm{~mm})$ emptying during fasted state. Various gastric emptying times were observed for non-disintegrating tablets of different sizes. The longest gastric emptying time was observed for $13 \mathrm{~mm}$ tablets (171 $\pm 13 \mathrm{~min})$, followed by $11 \mathrm{~mm}$ tablets $(128 \pm 17 \mathrm{~min})$ and $7 \mathrm{~mm}$ tablets (116 $\pm 19 \mathrm{~min}$ ) (Khosla, Davis, 1990).

It has been demonstrated, using radiolabeled technique, that there is a difference between gastric the emptying times of a liquid, digestible solid, and indigestible solid. It was suggested that the emptying of large $(91 \mathrm{~mm})$ indigestible objects from the stomach was dependent upon interdigestive migrating myoelectric complex. When liquid and digestible solids are present in the stomach, it contracts $\sim 3-4$ times per minute, leading to the movement of the contents through the partially opened pylorus. Indigestible solids larger than the pyloric opening are propelled back and several phases of myoelectric activity take place when the pyloric opening increases in size, during the housekeeping wave, and allows the sweeping of indigestible solids.

Studies have shown that the gastric residence time can be significantly increased under the fed conditions, since the MMC is delayed (Mojaverian et al., 1985). Several formulation parameters can affect gastric residence time. More reliable gastric emptying patterns are observed for multiparticulate formulations, as compared to single-unit formulations, which suffer from the "all or none concept." As the units of multiparticulate systems are distributed freely throughout the gastrointestinal tract, their transport is affected to a lesser extent by the transit time of food, when compared to single-unit formulations (Bechgaard, Ladefoged, 1978). Size and shape of dosage unit also affect gastric emptying.

The density of a dosage form also affects the gastric emptying rate. A buoyant dosage form having a density of less than that of the gastric fluids will float. Since it is away from the pyloric sphincter, the dosage unit is retained in the stomach for a prolonged period. Posture and nature of the meal also have an effect on gastric emptying.

Advantages of floating microspheres:

1. Bioavailability enhances, despite first pass effect, because fluctuations in plasma drug concentration are avoided, and a desirable plasma drug concentration is maintained by continuous drug release.

2. Superior to single-unit floating dosage forms, as such microspheres release drugs uniformly and there is no risk of dose dumping.

3. Enhanced absorption of drugs that solubilise only in stomach.

4. Site-specific drug delivery to the stomach can be achieved.

5. Avoidance of gastric irritation, due to sustained release effect.

6. Better therapeutic effect of short half-life drugs can be achieved.

Reproducibility of the particle size of the formulation is the main problem associated with floating microspheres (Mitsutoshi et al., 2001).

\section{METHODS OF PREPARATION OF HOLLOW MICROSPHERES}

Hollow microspheres are prepared through the solvent diffusion and evaporation method to create the hollow inner core. The solvent is evaporated either by increasing the temperature under pressure or by continuous stirring.

Sato et al. (2004c) prepared the floating microspheres by the emulsion solvent diffusion method, utilizing enteric acrylic polymers dissolved with drug in a mixture of dichloromethane and ethanol. The above solution was introduced in the aqueous solution of polyvinyl alcohol at $40^{\circ} \mathrm{C}$ with constant stirring to form an oil-in-water $(\mathrm{o} / \mathrm{w})$ emulsion. After agitating the system for 1 hour, the resulting polymeric particulate systems were sieved between 500 and $1000 \mathrm{~mm}$ and then dried overnight at $40{ }^{\circ} \mathrm{C}$ to produce hollow microspheres.

Jain et al. (2005) used the emulsion solvent diffusion technique with a modification. The drug was adsorbed on a porous carrier (calcium silicate). The drug-adsorbed porous carrier was added into the polymer solution 
(Eudragit $\mathrm{S}$ ) in the mixture of ethanol and dichloromethane (2:1) and sonicated using a probe sonicator. The resulting suspension was poured into an aqueous solution of polyvinyl alcohol $(0.75 \% \mathrm{w} / \mathrm{v})$ at $40{ }^{\circ} \mathrm{C}$. The emulsion was stirred at $500 \mathrm{rpm}$ employing a propeller-type agitator for 3 hours. The microspheres were separated by filtration, washed with water and dried at room temperature in a desiccators for 24 hours.

Wei et al. (2008) prepared hollow microspheres by using liquid paraffin as an external phase. Microspheres possessing an internal hollow structure were prepared using an oil-in-oil (o/o) emulsion solvent diffusionevaporation method. Drug and polymer were dispersed or dissolved in ethanol by ultrasonication at room temperature, followed by addition of ether. Then a suspension of drug and polymer was slowly emulsified into an agitated external phase of liquid paraffin containing Span-80 as surfactant at $30^{\circ} \mathrm{C}$. The dispersion system was stirred at a constant speed of $300 \mathrm{rpm}$ for 8 hours. When evaporation of solvents was complete, the hollow microspheres formed were separated by filtration, washed with n-hexane and dried in an air oven at $50^{\circ} \mathrm{C}$ for 12 hours before being stored in a desiccator.

Schmidt and Roessling (2006) developed a novel manufacturing process of gas-filled, hollow, poly-butyl2-cyanoacrylate (PBCA) microspheres in an aqueous phase. A novel two-step manufacturing process was developed to synthesize gas-filled hollow microspheres. This process is outlined in Figure 1. These microspheres have an organic shell. The first step is the polymerization process of $n$-butyl-2- cyanoacrylate (BCA) to form nanoparticles. During the second step, the nanoparticles attach on a microbubble precursor and finally form hollow microspheres.

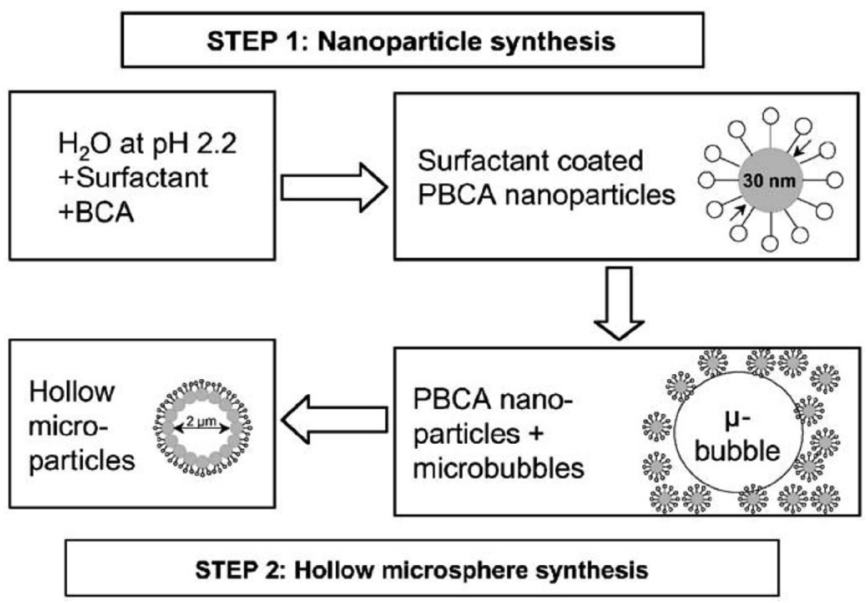

FIGURE 1 - Scheme of the two-step process for the synthesis of gas-filled hollow microspheres (Schmidt, Roessling, 2006).
Mitsutoshi et al. (2001) had given the continuous manufacturing method for preparation of microspheres and the apparatus thereof. This invention provides a method for continuously manufacturing microspheres comprising the following steps: transferring a pressurized dispersed phase into a continuous phase by force, via a plurality of microchannels having a predetermined width, in order to produce emulsions and withdrawing microspheres in the form of produced emulsions and fine particles suspended in liquid, etc., with the microspheres floating and sinking in response to their specific gravity.

Daniel, MacAusland and Baker (2011) have developed buoyant polymer particles for delivery of therapeutic agents to the central nervous system. The invention uses a biodegradable polymer composition containing a therapeutic agent, a polymer and a buoyancy agent. The given composition is controllably buoyant in cerebrospinal fluid. The degree of buoyancy is controlled by the various combinations and amounts of the buoyancy agent. The various buoyancy agents used with polymers are: mineral oil, isopropyl meristate, Labrifil 1944, vegetable oil, methyl oleate, lanoline, petrolatin, cetyl alcohol, corn oil, soybean oil, castor oil, air, nitrogen, argon, hydrofluorocarbons, carbondioxide, helium, and xenon.

Cellulose acetate, chitosan, Eudragit ${ }^{\circledR}$, Acrycoat, Methocel, polyacrylates, polyvinyl acetate, Carbopol, agar, polyethylene oxide, polycarbonates, acrylic resins and polyethylene oxide are some of the polymers used in the preparation of hollow microspheres.

\section{Mechanism of formation of hollow microspheres}

Ethanol and methanol have been found to be good solvents for most drugs and polymers. Dichloromethane and chloroform are good bridging liquids due to the good linkage between the drug and polymers and to their immiscibility in the external phase. Water-insoluble polymers, mentioned above, show higher solubility in dichloromethane than ethanol. However, ethanol has higher solubility in water. As soon as the polymer solution was added to the aqueous medium, the ethanol diffuses rapidly from the droplets of the polymer solution. Simultaneous diffusion of water inside the sphere further decreased the ethanol concentration, hence the polymer precipitated, resulting in the formation of microspheres. Dichloromethane remaining as the central core diffused slowly due to its low water solubility. Therefore, the diffusion of ethanol played an important role in determining the size and shape of the microspheres. The diagrammatic representation of mechanism of formation of floating microspheres is given in the Figure 2. The inner porous 
structure was attributed to the inward diffusion of water, which resulted in the solidification of the polymer and the formation of several smaller pockets of dichloromethane rich entrapments which diffused out together with ethanol. The entrapped dichloromethane diffused slowly out of the pocket giving a porous structure to the wall of the microspheres (Figure $3 b$ ). Due to the poor miscibility, water could not effectively invade the dichloromethane rich core. Therefore, the diffusion of dichloromethane began late, after the initial solidification, and formed a central hollow structure. During the diffusion of the solvents, the polymer was pulled outward as a result of the dragging force of the solvents and thus the central void space emerged. The central cavity produced by the solvents was gradually filled with water due to the reduced internal pressure. Water escaped out of the cavity during the drying process, ultimately forming hollow microspheres (Pushp, Myung, Hoo, 2007).

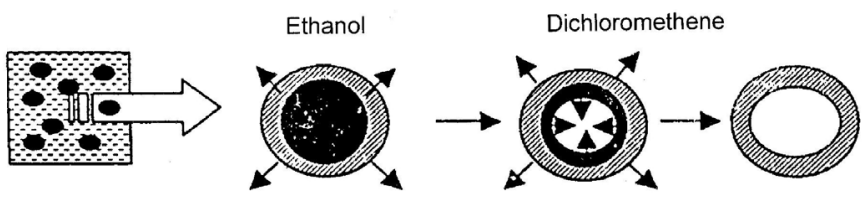

FIGURE 2 - Formulation of floating microspheres (Kawashima et al., 1991).

\section{Mechanism of gastroretention}

When microspheres come in contact with gastric fluid, the gel formers, polysaccharides, and polymers hydrate to form a colloidal gel barrier that controls the rate of fluid penetration into the device and drug release. As the exterior surface of the dosage form dissolves, the gel layer is maintained by the hydration of the adjacent hydrocolloid layer. The air trapped by the swollen polymer lowers the density and confers buoyancy to the microspheres. However, a minimal gastric content is needed to allow proper achievement of buoyancy.

Adherence to the wall of the stomach will be possible during the emptying process in both the fed and the fasted state, assuming that the mucoadhesive properties of the particles have not been modified by the stomach contents, in particular, non-adherent mucus (Figure 4).

\section{Process variables affecting physicochemical properties of hollow microspheres}

\section{Stirring rate}

Srivastava, Ridhurkar and Wadhwa (2005) have studied the effects of the stirring rate on microsphere par-
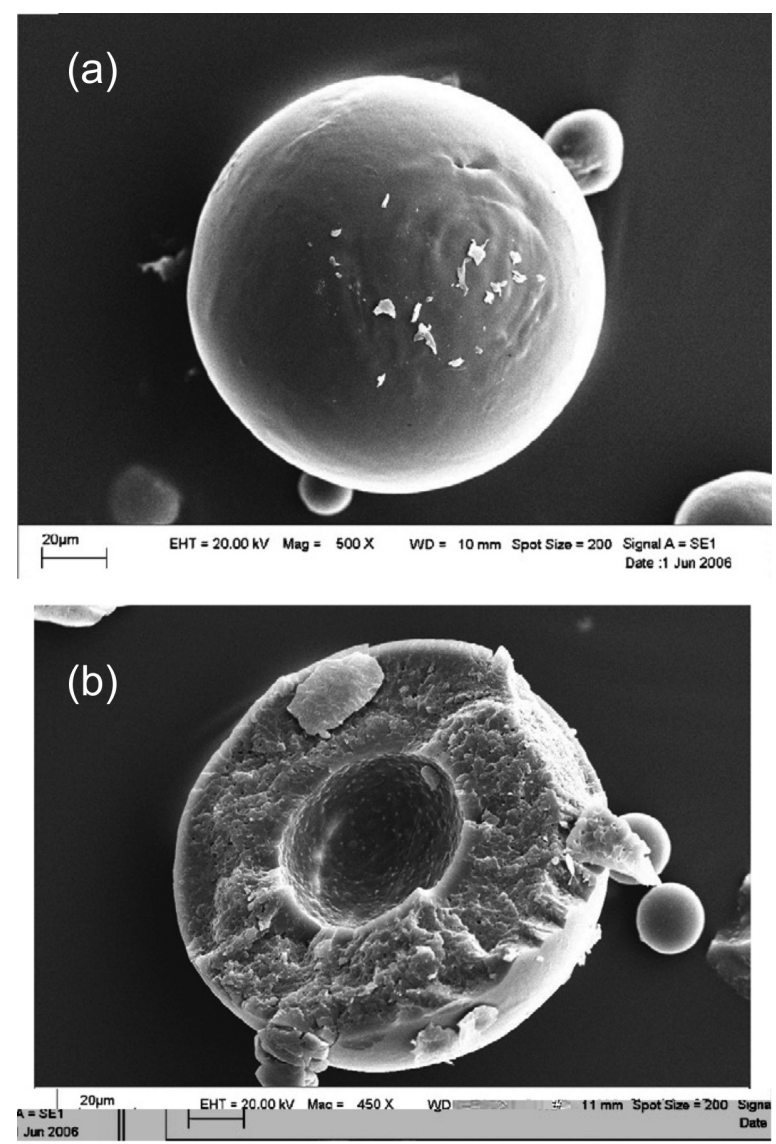

FIGURE 3 - SEM photographs of (a) outer surface of a microsphere, (b) inner surface of a broken half of a microsphere (Pushp, Myung, Hoo, 2007).

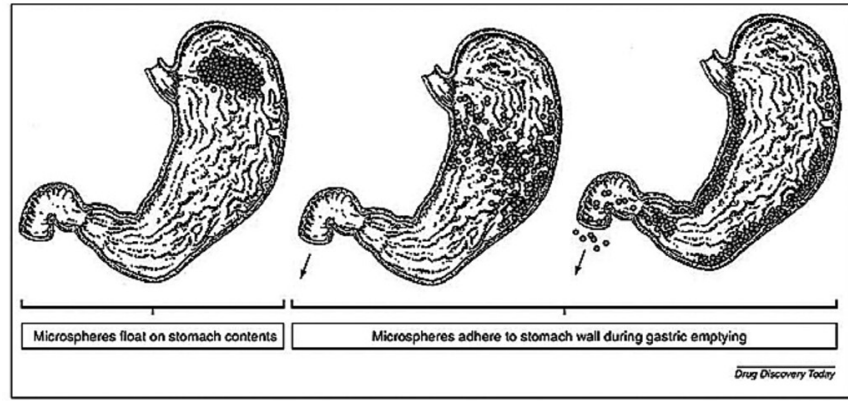

FIGURE 4 - Mechanism of gastroretention of floating microspheres having mucoadhesive polymer (Stanley, 2005).

ticle size. To observe the effect of agitation speed on the size of the resulting microspheres, formulations were prepared at varying agitation speeds; $300 \mathrm{rpm}, 500 \mathrm{rpm}, 1000$ $\mathrm{rpm}$. The size of the resulting microspheres decreased with increasing agitation, but the increase was not statistically significant. It may be inferred that the agitation speed in the study range was not able to break up the bulk of the polymer into finer droplets. 


\section{Temperature of preparation}

Sato et al. (2003b) have studied optimum preparation temperature with respect to microsphere cavity formation. The solution drug and polymer were poured into an aqueous solution of polyvinyl alcohol at various temperatures, i.e., $20,30,40$ and $50^{\circ} \mathrm{C}$. They concluded that preparation at 20 or $30^{\circ} \mathrm{C}$ provided porous microspheres having higher porosity with a surface so rough as to crumble upon touching. Although the respective apparent particle densities of the resulting hollow microspheres were low, both buoyancies were low, probably due to easy penetration of the dissolution medium through the porous surface. The roundness of hollow microspheres prepared at $40{ }^{\circ} \mathrm{C}$ was close to 1 ; moreover, surfaces were less rough than those of hollow microspheres prepared at 20 or 30 ${ }^{\circ} \mathrm{C}$. Hollow microspheres prepared at $50^{\circ} \mathrm{C}$ exhibited no hollow nature; however, a single large depression occurred on the surface. The hollow microspheres possessed high apparent particle density and low buoyancy due to the absence of a cavity. Few traces of evaporation were observed on the surface, which was attributable to the rapid evaporation of dichloromethane at temperatures beyond the boiling point $\left(40.2{ }^{\circ} \mathrm{C}\right)$. At $40{ }^{\circ} \mathrm{C}$, polymers and the drug were coprecipitated, and the shell was formed by the diffusion of ethanol into the aqueous solution and simultaneous evaporation of dichloromethane. In contrast, hollow microspheres prepared at $50^{\circ} \mathrm{C}$ demonstrated a single large depression on the surface, which was a consequence of the rapid evaporation of dichloromethane.

\section{Plasticizers}

Patil et al. (2009) have studied the effect of plasticizer concentration on the surface of microspheres and on the release of the drug. They have found that the addition of plasticizer made the wall of material more elastic and flexible, so that it never got brittle or ruptured under pressure. It was also observed that the release of the drug increased significantly with the increase of plasticizer concentration.

\section{Volume of aqueous phase}

Jain et al. (2005) have studied the effect of various volumes on the formation of hollow microspheres. Volumes of aqueous phase used were 200, 300, 400 and $500 \mathrm{ml}$ they observed that the potential advantage of using large volumes of the external aqueous phase was the reduction of the required stirring times. The solubility of dichloromethane in water is $1 \% \mathrm{w} / \mathrm{v}$. Using a larger volume (400 to $500 \mathrm{ml}$ ), the diffusion of dichloromethane into the aqueous phase, and hence the solidification of particles, occurred faster, when compared to a volume of $200 \mathrm{ml}$.

\section{Solvent ratio}

The bridging liquid plays a key role in microsphere preparation. When a good solvent diffuses into the poor solvent, which causes the precipitation of the drug and the polymer, a bridge liquid must be present in order to maintain the spherical shape of the microsphere. Too small a volume of the bridging liquid can lead to irregularly shaped microspheres while too large a volume of bridging liquid could prevent the emulsion droplets from solidifying. Therefore, the amount of dichloromethane needs to be carefully controlled (Hu et al., 2006).

The ratio of dichloromethane with ethanol also affected the morphology of the microspheres and the best results with spherical shape were obtained when the ratio of ethanol to dichloromethane was 2:1 (Jain et al., 2005).

\section{Amount of polymer and viscosity}

Gattani, Kawtikwar and Sakarkar (2009) have studied the effect of polymer concentration on in vitro release of aceclofenac from floating microspheres. Increased density of the polymer matrix at higher concentrations results in increased diffusional pathlength. This may decrease the overall drug release from the polymer matrix. Furthermore, smaller microspheres are formed at a lower polymer concentration and have a larger surface area exposed to dissolution medium, giving rise to faster drug release.

Srivastava, Ridhurkar and Wadhwa (2005) prepared microspheres using a gradually increasing ethyl cellulose concentration in combination with a fixed concentration of hydroxy propyl methyl cellulose (HPMC) to assess the effect of polymer concentration on the size of microspheres. Mean particle size of the microspheres significantly increased with increasing ethyl cellulose. The viscosity of the medium increases at a higher polymer concentration, resulting in enhanced interfacial tension. Shearing efficiency is also diminished at higher viscosities. This results in the formation of larger particles.

When viscosity is increased, the yield of hollow microspheres is decreased, and mean diameter and drug loading amount are increased (Wei, Zhao, 2008).

Baykara and Kiliçarslan (2003) have studied the effect of the drug-to-polymer ratio on the properties of verapamil $\mathrm{HCl}$ loaded microspheres. They found that the drug dissolution profile could be slowed down by increasing polymer amount in the formulations, and that particle size, surface characteristics of microspheres, and dissolution rate of verapamil could be modified through the variation of drug-to-polymer ratio.

\section{Effect of solvents}

Bornare et. al. (2009) have studied the effect of 
various organic solvents on the formation of microspheres by the solvent evaporation method. Dichloromethane was employed as polar internal organic solvent phase for preparation of microspheres because it is a good solvent for most of polymers and drugs. However, it was observed that the microspheres obtained were not at all spherical in shape. To solve this problem, methanol was used, along with dichloromethane, in the preparation of microspheres. The microspheres so obtained were spherical, but lacked smooth texture. To avoid this problem, various solvents were critically screened on the basis of the boiling points, such as dichloromethane $\left(39.75^{\circ} \mathrm{C}\right)$, acetone $\left(56.5^{\circ} \mathrm{C}\right)$, methanol $\left(64.7^{\circ} \mathrm{C}\right)$ and ethanol $\left(78.4^{\circ} \mathrm{C}\right)$. It was observed that the boiling point increased from DCM to ethanol and so instead of DCM/methanol, ethanol was tried. Ethanol is a good solvent for most water-soluble drugs and water-insoluble polymers, and it is non-toxic. It remained dispersed as droplets in the oily phase, leading to the formation of a stable emulsion. Ethanol may have worked because it has a high boiling point in relation to other organic solvents (dichloromethane, acetone, methanol etc.), which prevented immediate polymer precipitation. The researchers observed that the microspheres so obtained were completely spherical, with a smooth surface.

\section{Emulsifier concentration}

Nilkumhang and Basit (2009) have studied effect of emulsifier concentration on particle size. They found that the particle size and size distribution were increased when the surfactant concentration was reduced from $1 \%$ to $0.25 \%(\mathrm{w} / \mathrm{w})$. The role of the surfactant is to decrease the interfacial tension between the dispersed droplets and the continuous phase, as well as to protect the droplets from collision and coalescence. Low emulsifier concentrations may be insufficient to shield the entire droplet surface; droplets are more susceptible to collision and fusion. Also, at higher concentration of emulsifier, lower encapsulation efficiency and larger particle size were obtained, which suggests that the critical micelle concentration had been exceeded, which directly affected emulsion stability. Hence, the optimum concentration of the emulsifier should be identified.

\section{Release modifiers}

Many drugs are not released in significant amount from this type of microparticles at the $\mathrm{pH}$ of gastric fluids (Lee, Park and Choi, 1999). So, there is a need for some hydrophilic polymers to be added into the formulation. Streubel, Siepmann and Bodmeier (2002) have developed a multiparticulate, floating drug delivery system consist- ing of highly porous carrier material (foam powder), drug and polymer.

Various agents, such as HPMC, citric acid, PVP, PEG, etc., depending upon their properties, can be used to modify the drug release. These are also called as channeling agents.

Karthikeyan et al. (2008) have studied the effect of different viscosity grades of HPMC on the drug release profile. He used three different grades of HPMC in combination with various ratios of ethyl cellulose-to-HPMC. The various grades used were HPMC 15cp, HPMC K4M, and HPMC 100LV. The best release was found to be with the lowest viscosity grade of HPMC (HPMC 15cp) when compared to the other two viscosities (HPMC 100LV and HPMC K4M).

Sato et al. (2004b) have prepared floating microspheres for riboflavin from Eudragit S100. In the urinary excretion study, they found that the total urinary excretion of riboflavin following administration of hollow microspheres containing riboflavin was clearly lower than that of riboflavin powder, as very little riboflavin was released from the hollow microspheres into the dissolution medium ( $\mathrm{pH}$ 1.2). Thus, hollow microspheres were prepared by mixing with a water-soluble polymer, HPMC, in Eudragit S100. The objective of these hollow microspheres was to increase the amount of riboflavin released from the hollow microspheres into the dissolution medium and to increase overall urinary excretion of riboflavin.

\section{Characterization/evaluation of floating microspheres}

\section{Particle size}

Size is measured using an optical microscope, and mean particle size is calculated by measuring 200-300 particles with the help of a calibrated ocular micrometer.

Different sizes of microspheres and their distribution in each batch are measured by sieving in a mechanical shaker, using a nest of standard sieves (ASTM) and the shaking period of 15 minutes. Particle size distribution is determined and the mean particle size of microspheres is calculated by using the following formula (Badri et al., 1999).

Mean particle size $=\sum$ (mean particle size of the fraction $\times$ weight fraction $) / \sum$ (weight fraction)

\section{Tapped density and compressibility index}

The tapping method is used to determine the tapped density and percentage compressibility index, as follows (Sinko, 2006). 
Tapped density $=\frac{\text { Mass of microspheres }}{\text { Volume of microspheres after tapping }}$

$\%$ compressibility Index $=\left[1-\frac{V}{V_{0}}\right] \times 100$

where $V$ and $V_{o}$ are the volumes of the sample after and before the standard tapping, respectively.

\section{Surface morphology}

The external and internal morphology of the microspheres is studied by scanning electron microscopy (SEM).

\section{$\%$ Yield} tion.

The yield was calculated from the following equa-

$\%$ Yield $=\frac{\text { weight of hollow microspheres }}{\text { weight of drug taken }+ \text { total polymer weight }} \times 100$

Percentage of drug content / drug loading amount(\%)

A fixed amount of microspheres containing a drug are dissolved in a suitable solvent such as ethanol, methanol, etc. by ultrasonication. The solution is then filtered through a $5 \mu \mathrm{m}$ membrane filter. Finally, drug concentration is determined by the UV, spectrophotometrically. Drug content is calculated according to following equation:

$\%$ drug content $=\frac{\text { weight of drug in microspheres }}{\text { weight of microspheres recovered }} \times 100$

\section{Percentage of drug entrapment}

The percentage of drug entrapment can be calculated by the following equation.

$\%$ drug entrapment $=\frac{\text { calculated drug concentration }}{\text { theoritical drug content }} \times 100$

\section{Floating behavior}

The floating test on the microspheres is carried out using the dissolution method II apparatus, specified in the USP XXII. The microspheres are spread over the surface of the dispersing medium $(900 \mathrm{ml})$, which is agitated by a paddle rotated at $100 \mathrm{rpm}$. Disintegration test solution No. 1 ( $\mathrm{pH} 1.2)$, containing Tween 20 (0.02\%, w/v), was used as a dispersing medium to simulate gastric fluid. After agitation for a previously determined interval, the hollow microspheres that floated over the surface of medium and those that settled to the bottom of the flask were recovered separately. After drying, each fraction of the hollow microspheres was weighed. The buoyancy of the hollow microspheres was represented by the following equation (Kawashima et al., 1991).
$\operatorname{buoyancy}(\%)=\frac{Q_{f}}{Q_{f}+Q_{s}} \times 100$

where $Q_{\mathrm{f}}$ and $Q_{\mathrm{s}}$ are the weights of the floating and settled hollow microspheres, respectively.

In vivo buoyancy

Jain, Agarwal and Jain (2006a) have studied studied the gastric retention time of floating microspheres by gamma scintigraphy. The in vivo transit behavior of the floating and non floating microspheres was monitored using 12 one-year-old male albino rabbits. These rabbits were divided into two groups, i.e., group I and group II.

In order to standardize the conditions of GI motility, the animals were fasted for 12 hours prior to the commencement of each experiment. Floating microspheres $(100 \mathrm{mg})$ were orally administered in suspension form to the animals in group I and non-floating microspheres were administered to group II, followed by a sufficient volume of drinking water. The location of the formulation in the stomach was monitored by keeping the subjects in front of a gamma camera. In between the gamma scannings, the animals were freed and allowed to move and carry out normal activities, but were not allowed to ingest any food or water until the formulation had emptied the stomach completely.

Kawashima et al. (1991) prepared hollow microspheres made with Eudragit $\mathrm{S}$, containing barium sulfate as a contrast agent for the radiographical in vivo test. The study was carried out with two healthy male volunteers, free of detectable gastrointestinal diseases or disorders. Each subject, having fasted overnight, had a light Japanese breakfast (one rice ball and one cup of soup). After 30 minutes, each subject ingested two hard-gelatin capsules packed with hollow microspheres $(1000 \mathrm{mg})$, together with $100 \mathrm{ml}$ of water. The intragastric behavior of the hollow microspheres after dosing was observed by taking a series of X-ray photographs at suitable intervals. Cui et al. (2008) and Sato et al. (2004a) had performed the same study on healthy human volunteers, using gamma scintigraphy.

In vitro release studies

In vitro dissolution studies can be carried out in a USP paddle type dissolution assembly. Microspheres equivalent to the drug dose are added to $900 \mathrm{ml}$ of the dissolution medium and stirred at $100 \mathrm{rpm}$ at $37 \pm 0.5^{\circ} \mathrm{C}$. Samples are withdrawn at a specified time interval and analyzed by any suitable analytical method, such as UV spectroscopy or HPLC, etc.

Wei et al. (2008) used the same apparatus with the following modifications: the microspheres were intro- 
duced into a dialysis membrane bag with molecular weight cut off of 8000-12000. The test bag, which was tied and bound to the rotating paddle by a thread, was immersed in the dissolution medium; the rotating speed was $100 \mathrm{rpm}$.

In vivo studies

In vivo studies are generally conducted in healthy male albino rabbits weighing $2-2.5 \mathrm{~kg}$. The animals are fasted for 24 hours before the experiments; however, they are given free access to food and water during the experiments. Blood samples $(2 \mathrm{~mL})$ are collected from the marginal ear vein into heparinized centrifuge at an appropriate time interval (Wei, Zhao, 2008; Joseph, Lakshmi, Jayakrishnan, 2002).

Sato et al. (2003a) has carried out an in vivo study in healthy human volunteers. The pharmacokinetic parameters were determined by the analysis of urinary excretion data.

\section{Applications of floating microspheres}

1. Floating microspheres can be used as carriers for drugs with so-called absorption windows, these substances, for example antiviral, antifungal and antibiotic agents (sulphonamides, quinolones, penicillins, cephalosporins, aminoglycosides and tetracyclines) are taken up only from very specific sites of the GI mucosa.

2. Hollow microspheres of non-steroidal anti-inflammatory drugs are very effective for controlled release, and reduce the major side effect of gastric irritation. For example, floating microspheres of indomethacin are quite beneficial for rheumatic patients.

3. Floating microspheres are especially effective in the delivery of sparingly soluble and insoluble drugs. It is known that as the solubility of a drug decreases, the time available for drug dissolution becomes less adequate, and thus transit time becomes a significant factor affecting drug absorption. For weakly basic drugs that are poorly soluble at an alkaline $\mathrm{pH}$, hollow microspheres may avoid the risk of solubility becoming the rate-limiting step in release, by restricting such drugs to the stomach. Positioned gastric release is useful for drugs efficiently absorbed through the stomach, such as verapamil hydrochloride. The gastroretentive floating microspheres will beneficially alter the absorption profile of the active agent, thus enhancing its bioavailability.

4. Hollow microspheres can greatly improve the pharmacotherapy of the stomach through local drug release, leading to high drug concentrations at the gastric mucosa, thus eradicating Helicobacter pylori from the sub-mucosal tissue of the stomach and making it pos- sible to treat stomach and duodenal ulcers, gastritis and oesophagitis (Umamaheshwari et al., 2003).

TABLE I - List of the drugs formulated as a floating microspheres

Aspirin, griseofulvin and $p$-nitroaniline (Thanoo, Sunny, Jayakrishnan, 1993)

Ibuprofen (Kawashima et al., 1992)

Terfenadine (Jayanthi, Jayashwal, Srivastava, 1995)

Tranilast (Kawashima et al., 1992; Kawashima et al., 1991)

Ketoprofen (El-kamel et al., 2001)

Verapamil, Verapamil HCl (Soppimath et al., 2001; Baykara, Kiliçarslan, 2003; Tanwar, Naruka, Ojha, 2007)

Repaglinide (Jain et al., 2005)

Cimetidine (Srivastava, Ridhurkar, Wadhwa, 2005)

Orlistat (Jain, Agraval, Jain, 2006b)

Rosiglitazone (Kamila et al., 2009)

Nitrendipine (Cui et al., 2008)

Aceclofenac (Gattani, Kawtikwar, Sakarkar, 2009)

Acyclovir (Patil et al., 2009)

Cefpodoxime proxetil (Karthikeyan et al., 2008)

Ranitidine $\mathrm{HCl}$ (Wei, Zhao, 2008)

Riboflavin (Kawashima et al., 1991; Sato et al., 2003b; Sato et al., 2004b)

Piroxicam (Joseph, Lakshmi, Jayakrishnan, 2002)

Acetohexamic acid (Umamaheshwari et al., 2003)

\section{CONCLUSION}

Drug absorption in the gastrointestinal tract is a highly variable procedure and prolonging gastric retention of the dosage form extends the time for drug absorption. Floating controlled drug delivery systems are employed to solve this problem. Floating microspheres have been showing high potential for gastroretention and provide an efficient means of enhancing bioavailability and controlling the release of many drugs.

\section{ACKNOWLEDGEMENTS}

The authors wish to thank the All India Council of Technical Education (AICTE) for its financial support.

\section{REFERENCES}

AVACHAT, M.; DHAMNE, A. Gastric floating system. WO Patent 02, 102, 415. December 27, 2002. 
BADRI, V.N.; THOMAS, P.A.; PANDIT, J.K.; KULKARNI, M.G.; MASHELKAR, R.A. Preparation of non-porous microspheres with high entrapment efficiency of proteins by a (water-in-oil)-in-oil emulsion technique. J. Control. Release, v.58, p.9-20, 1999.

BAYKARA, T.; KILIÇARSLAN, M. The effect of the drug/ polymer ratio on the properties of the verapamil $\mathrm{HCl}$ loaded microspheres. Int. J. Pharm., v.52, p.99-109, 2003.

BECHGAARD, H.; LADEFOGED, K. Distribution of pellets in gastrointestinal tract. The influence on transit time exerted by the density or diameter of pellets. J. Pharm. Pharmacol., v.30, p.690-692, 1978.

BORNARE, P.N.; AVACHAT, A.M.; AVACHAT, M.K.; PATEL, K.B.; JAIN, K.S. Development and characterization of sustained release microspheres of ropinirole $\mathrm{HCl}$ : study of various process parameter. In: AAPS ANNUAL MEETING AND EXPOSITION, Los Angeles, 2009. Proceedings. Los Angeles: AAPS, 2009. T3219.

CALBET, J.A.L.; MACLEAN, D.A. Role of caloric content on gastric emptying in humans. J. Physiol., v.498, p.553-559, 1997.

CHAUHAN, B.; SHIMPI, S.; MAHADIK, K.R.; PARADKAR, A. Preparation and evaluation of floating risedronate sodium Gelucire® 39/01 matrices. Acta Pharm., v.54, p.205-214, 2004.

CHOE, S.Y.; NEUDECK, B.L.; WELAGE, L.S.; AMIDON, G.E.; BARNETT. J.L.; AMIDON, G.L. Novel method to assess gastric emptying in humans: the Pellet Gastric Emptying Test. Eur. J. Pharm. Sci., v.14, p.347-353, 2001.

CHRISTMANN, V.; ROSENBERG, J.; SEEGA, J.; LEHR, C.M. Simultaneous in vivo visualization and localization of solid oral dosage forms in the rat gastrointestinal tract by magnetic resonance imaging (MRI). Pharm. Res., v.14, p.1066-1072, 1997.

CUI, F.; WANG, J.; SHI, K.; YANG L.; WANG, S.; ZHANG, L. In vivo evaluation of a sustained-release multiple-unit floating system containing nitrendipine. Asian J. Pharm. Sci., v.3, p.151-157, 2008.

DANIEL, P.; MACAUSLAND, S.; BAKER, K. Buoyant polymer particles for delivery of therapeutic agents to the central nervous system. US Patent 7, 923, 032. April 12, 2011.
DAVE, B.S.; AMIN, A.F.; PATEL, M.M. Gastroretentive drug delivery system of ranitidine hydrochloride: formulation and in vitro evaluation. AAPS. Pharm. Sci. Tech., v.5, p.1$6,2004$.

DAVIS, S.S.; STOCKWELL, A.F.; TAYLOR, M.J.; HARDY, J.G.; WHAL LEY, D.R.; WILSON, C.G. The effect of density on the gastric emptying of single and multiple unit dosage forms. Pharm. Res., v.3, p.208-213, 1986.

DESAI, S.; BOLTON, S. Floating sustained release therapeutic compositions. US Patent 4, 814, 179. March 21, 1989.

DESHPANDE, A.A.; SHAH, N.H.; RHODES, C.T.; MALICK. W. Development of a novel controlled-release system for gastric retention. Pharm. Res., v.14, p.815-819, 1997.

DIETRICH, C.F.; BRADEN, B. Sonographic assessments of gastrointestinal and biliary functions. Best Pract. Res. Clin. Gastroenterol., v.23, p.353-367, 2009.

EL-KAMEL, A.H.; SOKAR, M.S.; AL GAMAL, S.S.; NAGGAR, V.F. Preparation and evaluation of ketoprofen floating oral drug delivery system. Int. J. Pharm., v.220, p.13-21, 2001.

FIX, J.A.; CARGILL, R.; ENGLE, K. Controlled gastric emptying. III. Gastric residence time of a non-disintegrating geometric shape in human volunteers. Pharm. Res., v.10, p.1087-1089, 1993.

FRANZ, M.; OTH, M. Sustained release bilayer buoyant dosage form. US Patent 5, 232, 704. August 3, 1993.

GATTANI, Y.S.; KAWTIKWAR P.S.; SAKARKAR, D.M. Formulation and evaluation of gastro retentive multiparticulate drug delivery system of aceclofenac. Int. J. Chem. Tech. Res., v.1, p.1-10, 2009.

GHOOS, Y.F.; MAES, B.D.; GEYPENS, B.J.; MYS, G.; HIELE, M.I.; RUTGEERTS, P.J.; VANTRAPPEN, G. Measurement of gastric emptying rate of solids by means of a carbonlabeled octanoic acid breath test. Gastroenterology, v.104, p.1640-1647, 1993.

GRIFFITH, G.H.; OWEN, G.M.; KIRKMAN, S.; SHIELDS, $\mathrm{R}$. Measurement of rate of gastric emptying using Chromium-51. Lancet, v.1, p.1244-1245, 1966. 
GRONING, R.; HEUN, G. Dosage forms with controlled gastrointestinal passage-studies on the absorption of nitrofurantion. Int. J. Pharm., v.56, p.111-116, 1989.

GRONING, R.; HEUN, G. Oral dosage forms with controlled gastrointestinal transit. Drug Dev. Ind. Pharm., v.10, p.527539, 1984.

GUPTA, P.K.; SAU-HUNG, S.; ROBINSON, J. Bioadhesive/ mucoadhesive in drug delivery to the gastrointestinal tract. In: LENAERTS, V.; GURNEY, R. (Eds.). Bioadhesive drug delivery system. Boca Raton: CRC Press, 1990. p.65-92.

HILTON, A.K.; DEASY, P.B. In vitro and in vivo evaluation of an oral sustained-release floating dosage form of amoxycillin trihydrate. Int. J. Pharm., v.86, p.79-88, 1992.

HIRTZ, J. The GIT absorption of drugs in man: a review of current concepts and methods of investigation. Br. J. Clin. Pharmacol., v.19, p.77S-83S, 1985.

HOFFMANN, LA-ROCHE. Sustained-release formulations. CA Patent 1, 073, 358, GB Patent, 1, 546, 448, May 23, 1979.

HOLT, S.; CERVANTES, J.; WILKINSON, A.A.; WALLACE, J.H.K. Measurement of gastric emptying rate in humans by real-time ultrasound. Gastroenterology, v.89, p.752-759, 1985.

HU, R.; ZHU, J.; CHEN, G.; SUN, Y.; MEI, K.; LI, S. Preparation of sustained-release simvastatin microspheres by the spherical crystallization technique. Asian J. Pharm. Sci., v.1, p.47-52, 2006.

HUNT, J.N.; STUBBS, D.F. The volume and energy content of meals as determinants of gastric emptying. J. Physiol., v.245, p. 209-225, 1975.

JAIN, S.K.; AGRAWAL, G.P.; JAIN, N.K. A novel calcium silicate based microspheres of repaglinide: In vivo investigations. J. Control. Release, v.113, p.111-116, 2006 a.

JAIN, S.K.; AGRAWAL, G.P.; JAIN, N.K. Evaluation of porous carrier-based floating orlistat microspheres for gastric delivery. AAPS. Pharm. Sci. Tech., v.7, p.E1-E9, 2006b.
JAIN, S.K.; AWASTHI, A.M.; JAIN, N.K.; AGRAWAL, G.P. Calcium silicate based microspheres of repaglinide for gastroretentive floating drug delivery: Preparation and in vitro characterization. J. Control. Release, v.107, p.300309, 2005.

JAYANTHI, G.; JAYASWAL, S.B.; SRIVASTAVA, A.K. Formulation and evaluation of terfenadine microballoons for oral controlled release. Pharmazie, v.50, p.769-770, 1995.

JOLLIFFE, D.M. Practical gastric physiology. CEACCP., v.9, p.173-177, 2009.

JOSEPH, N.; LAKSHMI, S.; JAYAKRISHNAN, A. A floatingtype oral dosage form for piroxicam based on hollow polycarbonate microspheres: in vitro and in vivo evaluation in rabbits. J. Control. Release, v.79, p.71-79, 2002.

KAMILA, M.M.; MONDAL, N.; GHOSH, L.K.; GUPTA, B.K. Multiunit floating drug delivery system of rosiglitazone maleate: development, characterization, statistical optimization of drug release and in vivo evaluation. AAPS. Pharm. Sci. Tech., v.10, p.887-899, 2009.

KARTHIKEYAN, D.; KARTHIKEYAN, M.; RAMASAMY, C. Effect of different viscosity grades of HPMC on drug release profile. J. Pharm. Res., v.1, p.23-28, 2008.

KAWASHIMA, Y.; NIWA, T.; TAKEUCHI, H.; HINO, T.; ITO, Y. Preparation of multiple unit hollow microspheres (microballoons) with acrylic resin containing tranilast and their drug release characteristics (in vitro) and floating behavior (in vivo). J. Control. Release, v.16, p.279-290, 1991.

KAWASHIMA, Y.; NIWA, T.; TAKEUCHI, H.; HINO, T.; ITOH, Y. Hollow microspheres for use as a floating controlled drug delivery system in the stomach. J. Pharm. Sci., v.81, p.135-140, 1992.

KEDZIEREWICZ, F.; THOUVENOT, P.; LEMUT, J.; ETIENNE, A.; HOFFMAN, M.; MAINCENT, P. Evaluation of peroral silicone dosage forms in humans by gammascintigraphy. J. Control. Release, v.58, p.195-205, 1999.

KHOSLA, R.; DAVIS, S.S. The effect of tablet size on the gastric emptying of non- disintegrating tablets. Int. J. Pharm., v.62, p.R9-R11, 1990. 
LEE, J.H.; PARK, T.G.; CHOI, H.K. Development of oral drug delivery system using floating microspheres. $J$. Microencapsulation, v.16, p.715-721, 1999.

MAMAJEK, R.C.; MOYER, E.S. Drug dispensing device and method. US Patent 4, 207, 890. June 17, 1980.

MAUGHAN, R.J.; LEIPER, J.B. Methods for the assessment of gastric emptying in humans: an overview. Diabetes Med., v.13, p.S6-S10, 1996.

McCLELLAND, G.R.; SUTTON, J.A. Epigastric impedance: a non invasive method for the assessment of gastric emptying and motility. Gut, v.26, p.607-614, 1985.

MITSUTOSHI N.; KIKUCHI, Y.; SANO, Y.; NABETANI, H.; KAWAKATSU, T.; KOBAYASHI, I.; TAKAO, H. Continuous manufacturing method for microspheres and apparatus. US patent 6, 177, 479. January 23, 2001.

MOJAVERIAN, P.; FERGUSON, R.K.; VLASSES, P.H.; ROCCI, M.R.J.R.; OREN, A.; FIX, J. A.; CALDWELL, L.J.; GARDNER, C. Estimation of gastric residence time of the heidelberg capsules in humans: effect of varying food composition. Gastroenterology, v.89, p.392-397, 1985.

NILKUMHANG, N.; BASIT, A.W. The robustness and flexibility of an emulsion solvent evaporation method to prepare pH-responsive microparticles. Int. J. Pharm., v.377, p.135-141, 2009.

OTH, M.; FRANZ, M.; TIMMERMANS, J. The bilayer floating capsule: a stomach-related drug delivery system for misoprostil. Pharm. Res., v.9, p.298-302, 1992.

PARADKAR, A.; KIRAN, K.M.; SHAH, M.H.; KETKAR, A.; MAHADIK, K.R. Effect of drug solubility and different excipients on floating behaviour and release from glyceryl monooleate matrices Int. J. Pharm. v.272, p.151-160, 2004.

PATIL, J.M.; HIRLEKAR, R.S.; GIDE, P.S.; KADAM, V.J. Trends in floating drug delivery systems. J. Sci. Ind. Res., v.65, p.11-21, 2006.

PATIL, M.P.; PATIL, H.S.; BHARAT, W.T.; VINOD, M.T.; PATIL, V.R. Formulation and in-vitro evaluation of floating microspheres of acyclovir. Arch. Pharm. Sci. Res., v.1, p.194-198, 2009.
PONCHEL, G.; IRACHE, J.M. Specific and non-specific bioadhesive particulate system for oral delivery to the gastrointestinal tract. Adv. Drug Del. Rev., v.34, p.191-219, 1998.

PUSHP, R.N.; MYUNG, K.C.; HOO, K.C. Preparation of floating microspheres for fish farming, Int. J. Pharm., v.341, p.85-90, 2007.

REDNICK, A.B.; TUCKER, S.J. Sustained release bolus for animal husbandry. US patent 3, 507, 952. April 22, 1970.

RHIE, J.K.; HAYASHI, Y.; WELAGE, L.S.; FRENS, J.; WALD, R.J.; BARNETT, J.L.; AMIDON, G. E.; PUTCHA, L.; AMODON, G. L. Drug marker absorption in relation to pellet size, gastric motility and viscous meals in humans. Pharm. Res., v.15, p.233-238, 1998.

SATO, Y.; KAWASHIMA, Y.; TAKEUCHI, H.; YAMAMOTO, H. FUJIBAYASHI, Y. Pharmacoscintigraphic evaluation of riboflavin-containing microballoons for a floating controlled drug delivery system in healthy humans. $J$. Control. Release, v.98, p.75-85, 2004a.

SATO, Y.; KAWASHIMA, Y.; TAKEUCHI, H.; YAMAMOTO, $H$. In vitro and in vivo evaluation of riboflavin-containing microballoons for a floating controlled drug delivery system in healthy humans. Int. J. Pharm., v.275, p.97-107, 2004b.

SATO, Y.; KAWASHIMA, Y.; TAKEUCHI, H.; YAMAMOTO, $H$. In vitro evaluation of floating and drug releasing behaviors of hollow microspheres (microballoons) prepared by the emulsion solvent diffusion method. Eur. J. Pharm. Biopharm., v.57, p.235-243, 2004c.

SATO, Y.; KAWASHIMA, Y.; TAKEUCHI, H.; YAMAMOTO, $H$. In vivo evaluation of riboflavin-containing microballoons for floating controlled drug delivery system in healthy human volunteers. J. Control. Release, v.93, p.39-47, 2003 a.

SATO, Y.; KAWASHIMA, Y.; TAKEUCHI, H.; YAMAMOTO, $\mathrm{H}$. Physicochemical properties to determine the buoyancy of hollow microspheres (microballoons) prepared by the emulsion solvent diffusion method. Eur. J. Pharm. Biopharm., v.55, p.297-304, 2003 b.

SCHMIDT, W.; ROESSLING, G. Novel manufacturing process of hollow polymer microsphere. Chem. Eng. Sci., v.61, p.4973-4981, 2006. 
SHETH, P.R.; TOSSOUNIAN, J.L. Novel sustained release tablet formulations. US Patent 4, 167, 558, September 11, 1979.

SHETH, P.R.; TOSSOUNIAN, J.L. Sustained release pharmaceutical capsules. US patent $4,126,672$. November 21, 1978.

SHWETA, A.; JAVED, A.; ALKA, A.; ROOP, K.K.; SANJULA, B. Floating drug delivery systems: a review. AAPS Pharm. Sci. Tech., v.6, p.E372-E390, 2005.

SINGH, B.N.; KWON, H.K. Floating drug delivery systems: an approach to oral controlled drug delivery via gastric retention. J. Control. Release, v.63, p.235-259, 2000.

SINKO, P.J. Micrometrics. In: MARTIN, A. (Ed.) Martin's physical pharmacy and pharmaceutical science. 5.ed. Philadelphia: Lippincott Willians and Wilkins/a Wolters Kluwer Company, 2006. p.553-559.

SOPPIMATH, K.S.; KULKARNI, A.R.; RUDZINSKI, W.E.; AMINABHAVI, T.M. Microspheres as floating drug delivery systems to increase gastric retention of drugs. Drug Metab. Rev., v.33, p.149-160, 2001.

SRIVASTAVA, A.K.; RIDHURKAR, D.N.; WADHWA, S. Floating microspheres of cimetidine: Formulation, characterization and in vitro evaluation. Acta Pharm., v.55, p.277-285, 2005.

STANLEY, S.D. Formulation strategies for absorption windows. DDT, v.10, p.249-257, 2005.

STREUBEL, A.; SIEPMANN J.; BODMEIER R. Floating microparticles based on low density foam powder. Int. J. Pharm., v.241, p.279-292, 2002.
TANWAR, Y.S.; NARUKA, P.S.; OJHA, G.R. Development and evaluation of floating microspheres of verapamil hydrochloride. Rev. Bras. Ciênc. Farm., v.43, p.529-534, 2007.

THANOO, B.C.; SUNNY, M.C.; JAYAKRISHNAN, A. Oral sustained-release drug delivery systems using polycarbonate microspheres capable of floating on the gastric fluid. J. Pharm. Pharmacol., v.45, p.21-24, 1993.

UMAMAHESHWARI, R.B.; JAIN, S.; BHADRA, D.; JAIN, N.K.; Floating microspheres bearing acetohydroxamic acid for the treatment of helicobacter pylori. J. Pharm. Pharmacol., v.55, p.1607-1613, 2003.

URGUHART, J.; THEEUWES, F. Drug delivery system comprising a reservoir containing a plurality of tiny pills. US patent 4, 434, 153. February 28, 1994.

VELEHIK, M.G.; REYNOLDS, J.C.; ALAVI, A. The effect of meal energy content on gastric emptying. J. Nucl. Med., v.30, p.1106-1110, 1989.

WEI, Y.; ZHAO, L. In vitro and in vivo evaluation of ranitidine hydrochloride loaded hollow microspheres in rabbits. Arch. Pharm. Res., v.31, p.1369-1377, 2008.

WILDING, I.R.; COUPE, A.J.; DAVIS, S. S. The role of g-scintigraphy in oral drug delivery. Adv. Drug Del. Rev., v.46, p.103-124, 2001

WILSON, C.G.; WASHINGTON, N. The stomach: its role in oral drug delivery. In: RUBINSTEIN M.H., (Ed.) Physiological pharmaceutical: biological barriers to drug absorption. Chichester: Ellis Horwood, 1989. p.47-70.

Received for publication on $12^{\text {th }}$ April 2011 Accepted for publication on $08^{\text {th }}$ June 2011 